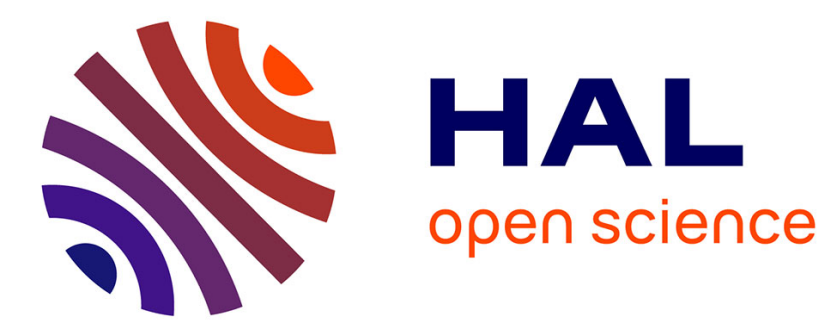

\title{
The relationship between deductive reasoning and the syntax of language in Broca's area: A review of the neuroimaging literature
}

Jérôme Prado

\section{- To cite this version:}

Jérôme Prado. The relationship between deductive reasoning and the syntax of language in Broca's area: A review of the neuroimaging literature. Annee Psychologique, 2018. hal-02346871

\section{HAL Id: hal-02346871 \\ https://hal.science/hal-02346871}

Submitted on 5 Nov 2019

HAL is a multi-disciplinary open access archive for the deposit and dissemination of scientific research documents, whether they are published or not. The documents may come from teaching and research institutions in France or abroad, or from public or private research centers.
L'archive ouverte pluridisciplinaire HAL, est destinée au dépôt et à la diffusion de documents scientifiques de niveau recherche, publiés ou non, émanant des établissements d'enseignement et de recherche français ou étrangers, des laboratoires publics ou privés. 
The relationship between deductive reasoning and the syntax of language in Broca's area: A review of the neuroimaging literature

\author{
Jérôme Prado \\ Institut des Sciences Cognitives Marc Jeannerod - UMR 5304, Centre National de la \\ Recherche Scientifique (CNRS) \& Université de Lyon, France
}

\title{
French title
}

La relation entre le raisonnement déductif et la syntaxe du langage dans l'aire de Broca : Une revue de la littérature en neuroimagerie

\section{Running title}

The relationship between deductive reasoning and language

\begin{abstract}
Author Note
Correspondence concerning this article should be addressed to Jérôme Prado (jprado@,isc.cnrs.fr), Institut des Sciences Cognitives Marc Jeannerod - UMR 5304, Centre National de la Recherche Scientifique (CNRS) \& Université de Lyon, 67 Boulevard Pinel, 69675 Bron cedex, France.
\end{abstract}

\section{Acknowledgments}

This research was supported by a grant from the Agence Nationale de la Recherche (ANR-14-CE30-0002). 


\begin{abstract}
A remarkable feature of the human brain is its ability to make deductions, that is, to infer valid conclusions from known information. In part because these deductions play an important role in spoken and written communication, it has been postulated that there is a close relationship between language and deductive reasoning in humans. Notably, some have proposed that deductive reasoning relies on a system of inferential rules that can be compared to the grammar of a natural language. Here I review the neuroimaging literature on deductive reasoning to evaluate whether there is some overlap between the neuro-cognitive operations that enable deduction and those that underlie the syntactic processing of language. Although some studies suggest that relatively simple deductions may involve Broca's area, no study to date has demonstrated that the mechanisms supporting the syntactic processing of language contribute to deductive reasoning. Implications for future directions in the literature are outlined.
\end{abstract}




\begin{abstract}
French)
Une caractéristique remarquable du cerveau humain est sa capacité à faire des déductions, c'est-à-dire à déduire des conclusions valides à partir d'informations connues. En partie parce que ces déductions jouent un rôle important dans la communication orale et écrite, il a été postulé qu'il pourrait exister une relation étroite entre le langage et le raisonnement déductif chez l'être humain. Certains ont notamment proposé que le raisonnement déductif reposerait sur un système de règles inférentielles qui pourraient être comparées à la grammaire d'un langage naturel. Dans cet article, je passe en revue la littérature en neuroimagerie sur le raisonnement déductif afin d'évaluer si les opérations neuro-cognitives qui sous-tendent le raisonnement déductif sont similaires à celles qui sous-tendent le traitement syntaxique du langage. Bien que certaines études suggèrent que des déductions relativement simples pourraient reposer sur l'aire de Broca, aucune étude à ce jour n'a démontré que les mécanismes soutenant le traitement syntaxique du langage contribuent au raisonnement déductif. Les implications de cette revue sur les recherches futures sont mentionnées.
\end{abstract}


(1) “Jerry was trying to decide what to wear to meet his fiancée's parents.

(2) 'I'd like to wear either my striped or my checkered shirt,' he thought.

(3) 'If I wear my striped shirt, I'll have to wear my blue pants since they match the shirt,' he thought, 'but I'm not sure where my blue pants are.'

(4) He looked in his closet for his checkered shirt and saw that it was wrinkled, so he decided he could not wear that.

(5) 'So I'd better find my blue pants,' he thought"

(Lea, O'Brien, Fisch, Noveck, \& Braine, 1990)

Readers do not have much difficulty understanding short stories such as the one above. Critical to this capacity are certain logical inferences that are carried out routinely. For example, sentence (4) eliminates one of the options from sentence (2), thus allowing the reader to infer that Jerry will have to wear his striped shirt (which is information that is never explicitly stated in the text). Additionally, the reader needs to integrate this inferred information with sentence (3) to understand why Jerry has to find his blue pants. These inferences are necessary for understanding the conclusion of the story.

Such inferences are deductive: a conclusion that follows from them has to be true if the premises are true. For example, this is the case for each of the arguments exemplified in Table 1, which rely on propositional connectives (e.g., modus ponens, modus tollens, disjunction elimination), linear relations, and inclusion of sets. Deductive reasoning is at the core of many of our cultural and scientific practices, including mathematics (Michal \& Ruhama, 2008; Nunes et al., 2007), law (Ellsworth, Holyoak, \& Morrison Jr, 2005) and medicine (Wulff, 1986). Deductive inferences play an important role in argumentation (Mercier \& Sperber, 2011) and, as the story above illustrates, are made rather automatically when processing written discourse 
(Lea, 1995). In fact, spontaneous deductive inferences are central, not only to written communication but to discourse generally. They are particularly critical to spoken discourse because speakers have to be understood on the fly (and thus inferences have to be made as sentences are spoken). For instance, a propositional inference such as modus ponens (see Table 1) is so automatic that it may be carried out without reasoners even being aware of it (Reverberi, Shallice, D'Agostini, Skrap, \& Bonatti, 2009). Thus, many of the deductive inferences that people make are likely to be drawn automatically in understanding discourse, whether written or spoken. This suggests that one of the most important functions of deductive reasoning is to facilitate verbal interaction (Braine, 1990).

Table 1 about here

\section{The hypothesis of deductive reasoning as a rule-based process}

Based on the observations above, several researchers have postulated a close relationship between language and deductive reasoning in humans. For example, Polk and Newell have claimed that "the central processes in deductive reasoning are linguistic" because they involve a verbal encoding of the premises into some kind of internal representation (Polk $\&$ Newell, 1995). But it is possible that processes akin to those involved in natural language are engaged well after this initial verbal encoding of the premises. Indeed, two important theories of human deductive reasoning -- PSYCOP (Rips, 1994) and the Mental Logic (Braine \& O'Brien, 1998) - posit that the core operations of deduction may rely on a system of contentfree rules. These theories, which are rooted in the Aristotelian idea that the mind possesses some kind of innate mental logic, rely on the assumption that formal rules are used to infer a 
conclusion from premises in a way that takes into account only their form (not their meaning). In some ways, these rules can be compared to the grammar of a natural language. In other words, this formal rule approach sees deductive reasoning as emerging from our ability to combine discrete structural elements into sequences, given a limited set of rules. Much like grammatical rules are applied to words to construct sentences, logical rules may be applied to a propositional representation of the premises to infer conclusions (Braine \& O'Brien, 1998; Rips, 1994). Basic inferential rules would involve (at least) the basic propositions and, if and or. For example, the 12 elementary rules (also called schemas) proposed by the Mental Logic are represented in Table 2 (Braine \& O'Brien, 1998).

Table 2 about here

How would this system of rules be used to draw deductive inferences? Consider for instance the Modus Ponens argument in Table 1. The rule [If P then Q; P; therefore Q] (schema 7 in Table 2) would be applied to the major premise If there is a circle then there is a triangle and the minor premise There is a circle to infer the conclusion There is a triangle. Similarly, in the case of the disjunction elimination argument in Table 1, the rule [P or Q; not-P; therefore Q] (schema 3 in Table 2) would be applied to the major premise There is a circle or there is a triangle and the minor premise There is not a circle to infer the conclusion There is a triangle. However, understanding more complex arguments such as Modus Tollens would require several cognitive steps. This is because the rule [If P then Q; not-Q; therefore not-P] is not believed to be part of the basic deductive competence (which is the reason why it is missing from Table 2). In such cases, strategies that are not universally available can be applied so that 
reasoners can go beyond their basic competence (e.g., strategies involving reductio ad absurdum: If circle were true, then triangle would have to be true, but triangle is false, so circle must be false).

In principle, one can extend this formal rule approach to relational premises as well. This would require incorporating axioms for transitivity, or meaning postulates, to the set of rules (Goodwin \& Johnson-Laird, 2005; Hagert, 1984; Johnson-Laird, 2010). For example, the relation is larger than might be associated with the transitive inferences below:

If $\mathrm{x}$ is larger than $\mathrm{y}$, and $\mathrm{y}$ is larger than $\mathrm{z}$, then $\mathrm{x}$ is larger than $\mathrm{z}$.

Such inferences can easily be applied to premises such as The circle is larger than the triangle and The triangle is larger than the square to derive the conclusion The circle larger the square in Table 1.

Finally, rules could also be applied to categorical arguments. This might be done by assuming that the repertoire of formal rules extend to those that involve quantifiers (Braine, 1998), or by assuming that there are rules that transform categorical premises into quantifierfree representations prior to syntactic manipulation (Rips, 1994). Consider for example the categorical argument at the bottom of Table 1. The premise All tables are triangles and All triangles are blue could be transformed into the premises If $x$ is a table then $x$ is a triangle and If $x$ is a triangle then $x$ is blue. Integrating these now-propositional premises would lead to the quantifier-free conclusion If $x$ is a table then $x$ is blue. Another rule might re-introduce the quantifier so that the conclusion would be translated into All tables are blue.

Deductive reasoning and the syntax of language: Common or different mechanisms? 
The hypothesis that deductive reasoning may rely on content-free rules prompts an intriguing question: Does deductive reasoning make use of some of the syntactic machinery that is used to produce sentences in natural language? As argued elsewhere, this question is fundamental because it pertains to the long-standing idea that human thought might be embedded in language (e.g., Monti \& Osherson, 2012). It is important to emphasize, however, that this idea is far from trivial in the cognitive literature, at least for two reasons.

First, over the past two decades or so, the idea that deductive reasoning would rely on rules of inference has been seriously challenged. For example, Johnson-Laird and colleagues (Johnson-Laird, 1999) have famously argued that deductive reasoning is not a rule-based process, but rather a process that involves the manipulation of a representation of the premises in spatial working memory. This popular theory, called the Mental Model Theory of reasoning, does not assume any role for rule-based representations in deduction. More recently, it has also been claimed that people use everyday probabilistic reasoning when making deductive inferences (Oaksford, 2015; Oaksford \& Chater, 2001, 2007). As such, this probabilistic view of deductive reasoning also denies the existence of a content-free rules of inference.

Second, even if one assumes that formal rules may underlie deductive reasoning, this does not necessarily mean that deductive reasoning and language rely on the same syntactic processes. For instance, as argued by Parsons \& Osherson (2001, p. 963), "the language that supports deduction [...] need not be a natural language like English, burdened as it is by ambiguity and ellipsis. Deduction (as well as other forms of reasoning) might rather be performed in a format that is antecedent to natural language, the latter being acquired for the purpose of expressing meanings that exist prior to their linguistic expression". In other words, it is entirely possible that deductive reasoning may be licensed by content-free rules relying on syntactic processes that are distinct from those supporting natural language. More 
generally, this harks back to the broader question of whether there exist some generalized mechanisms that govern all syntactically structured domains, such as language, math, music, or reasoning (Fadiga, Craighero, \& D’Ausilio, 2009; Monti, 2017; Tettamanti \& Weniger, 2006). Therefore, although evidence that deductive reasoning and the syntax of natural language rely on common mechanisms would arguably provide support for the formal rule approach to reasoning, evidence to the contrary would not necessarily mean that deductive reasoning is not a rule-based process.

Bearing this context in mind, neuroimaging studies appear uniquely suited to test whether deductive reasoning makes use of some of the syntactic processes supporting natural language. Indeed, there is a long-standing literature investigating the neural bases of syntactic processing in natural language. Perhaps the brain region that has been the most consistently associated with such processing is Broca's area (i.e., the brain region that corresponds to Brodmann areas, or BAs, 45 and 44) (Friederici \& Kotz, 2003; Grodzinsky \& Santi, 2008; Ullman, 2001). For example, studies have demonstrated enhanced activity in Broca's area when syntactically complex sentences (e.g., The juice that the child spilled stained the rug) are compared to syntactically simple sentences (e.g., The child spilled the juice that stained the rug) (Ben-Shachar, Hendler, Kahn, Ben-Bashat, \& Grodzinsky, 2003; Friederici, Fiebach, Schlesewsky, Bornkessel, \& von Cramon, 2006; Roder, Stock, Neville, Bien, \& Rosler, 2002; Stromswold, Caplan, Alpert, \& Rauch, 1996), or when syntactic violations are detected (e.g., The shirt was on ironed vs. The shirt was ironed) (Friederici, Ruschemeyer, Hahne, \& Fiebach, 2003; Meyer, Friederici, \& von Cramon, 2000). Grodzinsky and colleagues have suggested that activation of Broca's area is sensitive to the amount of syntactic movement (the displacement of an argument from its canonical position) in a sentence. For example, a sentence involving a lot of syntactic movement such as The mother of Jim loves the woman who the mailman and Kate burnt elicits more activity in Broca's area than a sentence associated with less syntactic 
movement such as The mailman and the mother of Jim love the woman who Kate burnt (BenShachar et al., 2003; Ben-Shachar, Palti, \& Grodzinsky, 2004; Grodzinsky \& Santi, 2008). In line with these neuroimaging findings, patients with lesion in Broca's area cannot understand sentences with movement but understand sentences without movement (Grodzinsky \& Santi, 2008). Overall, and although other regions have been associated with syntactic processing in the literature (e.g., the superior temporal gyrus, Friederici \& Kotz, 2003), there is ample evidence that syntactic processing in natural language is primarily supported by Broca's area. This makes this region a prime candidate for a potential overlap between deductive reasoning and the syntax of language.

The goal of the present review is to examine the hypothesis that deductive reasoning is associated with enhanced activity in brain areas that are also involved in the syntactic processing of language (and especially Broca's area). In what follows, I first describe some common features of the paradigms that are typically used to study the neural bases of deductive reasoning. In doing so, I want to draw the reader's attention on some methodological issues and caveats associated with these neuroimaging studies. These issues are important to keep in mind when interpreting the results of neuroimaging studies. I then turn to the neuroimaging literature investigating deductive reasoning in the absence of tasks investigating linguistic processing. These studies include early investigations focusing on the conclusion processing stage of a deductive argument, as well as a set of more recent studies focusing on the premise processing stage. Finally, I review more recent studies that have focused on directly comparing brain activity associated with deductive reasoning and linguistic processing.

\section{Some issues and caveat when investigating the neural bases of deductive reasoning}

In a typical neuroimaging experiment on deductive reasoning, participants are visually or auditorily presented with 2 to 3 premises, followed by a conclusion (see Fig. 1). The task 
typically requires participants to evaluate whether that conclusion follows out of necessity from the premises. Although such a design might not appear that different from designs that are used in behavioral studies, the neuroimaging environment requires some adaptations to be made to standard paradigms. This may give rise to issues that have to be taken into consideration when assessing results from neuroimaging studies. I will highlight here four of the most important issues (see also Monti \& Osherson, 2012; Monti, Osherson, Martinez, \& Parsons, 2007; Prado, Chadha, \& Booth, 2011; Reverberi et al., 2007; Reverberi, Rusconi, Paulesu, \& Cherubini, 2009).

Figure 1 about here

First, whereas behavioral studies typically present a large number of participants with one (or a few) reasoning problems to solve, neuroimaging experiments typically present a limited number of participants (e.g., between 15 to 20 participants) with a large number of trials (e.g., from 20 to 40 trials). Although this is done to maximize signal-to-noise ratio, this strategy may come with some experimental complications. For instance, by the end of the neuroimaging session, participants may develop strong expectations regarding the task and may employ memory or heuristic strategies to solve problems (rather than genuine reasoning; Reverberi et al., 2009). This confound may be especially prevalent in studies that extensively train participants on the reasoning task before even entering into the scanner (generally to maximize accuracy or to select participants based on their performance). A typical strategy to limit this bias is to make the task as varied as possible. For instance, participants may be presented with filler trials as well as with a variety of logical forms (Mathieu, Booth, \& Prado, 2015; Prado et 
al., 2015; Prado, Van Der Henst, \& Noveck, 2010; Schwartz, Epinat-Duclos, Léone, \& Prado, 2017).

Second, it is important to emphasize that any results from a brain imaging experiment need to be interpreted as a difference in activity between two cognitive states. That is, activity associated with deductive reasoning is always measured relative to a control or baseline condition. In some cases, this baseline may be a "low-level" control condition such as a fixation cross (which would then correspond to some sort of resting state). Of course, any activity associated with solving a deductive argument compared to such a resting state may be confounded by activity associated with reading the argument or selecting a response (which are processes that are not controlled for by the simple perception of a fixation cross). Therefore, such contrasts are not particularly useful when evaluating whether deductive reasoning involves linguistic processes that go beyond the mere reading of a triplet of sentences. More informative are undoubtedly contrasts in which activity associated with reading and response selection is subtracted out from activity associated with evaluating a deductive argument. Researchers have used a variety of such "high-level" baseline conditions across studies. For example, some have used arguments in which premises and/or conclusions are not related to one another (Goel, Buchel, Frith, \& Dolan, 2000; Goel \& Dolan, 2001, 2004), arguments in which the conclusion is the repetition of one premise (Noveck, Goel, \& Smith, 2004), or arguments that are easier to process than the type of arguments that is investigated (Monti et al., 2007; Prado, Mutreja, \& Booth, 2013). This is not to say that all of these "high-level" control conditions lead to the exact same interpretations regarding the effects observed. Variations in these control conditions also need to be taken into consideration when interpreting results. However, "high-level" baselines controlling for processes such as reading are a bare minimum when assessing the hypothesis that deductive reasoning may rely on the neural substrates of syntactic processing in language. 
Third, although behavioral investigations of deductive reasoning are mainly concerned with whether a conclusion is endorsed or not, neuroimaging studies are interested in what type of brain activity is associated with deductive reasoning. Reasoning, however, is a complex process that is diffuse and somewhat difficult to pinpoint temporarily. At what point during the processing of a deductive argument should we expect reasoning-related activity? While most researchers have focused on brain activity associated with the conclusion (Goel et al., 2000; Goel \& Dolan, 2001, 2003, 2004; Monti et al., 2007; Monti, Parsons, \& Osherson, 2009; Noveck et al., 2004; Stollstorff, Vartanian, \& Goel, 2012), others have argued that an inference is made as soon as the second premise appears and can be integrated with the first premise (Prado et al., 2010; Reverberi et al., 2012; Reverberi et al., 2010; Reverberi et al., 2007). Therefore, some studies have specifically investigated brain activity elicited by the second premise rather than the conclusion. Of course, there is no right or wrong answer to the question of when reasoning occurs. But it is important to keep in mind that studies vary in terms of conceptual choices made by the experimenters.

Fourth, as exemplified in Table 1, deductive argument may come in many forms. While all deductive arguments have in common the central feature that a conclusion follows out of necessity from the premises, multiple logical forms have rarely been used and compared in one single study. In other words, it is possible that the results obtained in one study using a specific logical form (e.g., propositional reasoning) may not translate to another study using a different form (e.g., relational reasoning). The idea that different forms of reasoning would rely on different types of mechanisms was in fact acknowledged by proponents of a formal rule approach of reasoning, who for example argued that "mental models in some form also provide a tool available to the human reasoning. Constructing models seems an intuitively natural way of solving the kind of spatial problems discussed by Johnson-Laird and Byrne" (Braine \& O'Brien, 1998, p.193-194). Thus, it is possible that different types of logical arguments may be 
associated with different types of brain mechanisms. Inter-study variability in terms of logical forms also needs to be kept in mind.

Overall, neuroimaging investigations of deductive reasoning come with a number of methodological and conceptual questions that experimenters have to face. As pointed out by Vinod Goel, a pioneer in the neuroimaging study of deductive reasoning, "there are no absolutely right or wrong answers to these and other similar issues. In making these decisions and compromises it is advisable to pay as much attention to the neuroscience as to the cognitive theory" (Goel, 2007). In the following, I will try to keep these issues in mind when reviewing relevant studies.

\section{Evidence for reliance on linguistic processing in early neuroimaging studies focusing on the conclusion processing stage of a deductive argument}

The hypothesis that deductive reasoning may rely on brain regions supporting linguistic processing was already at the center of the very first positron emission tomography (PET) study on deductive reasoning 20 years ago (Goel, Gold, Kapur, \& Houle, 1997). At the time, Goel and colleagues posited that, according to a formal rule approach, "deductive reasoning, being a formal, rule-governed process defined over the structure of language, will activate the left hemisphere more than the right hemisphere and will implicate some of the same structures involved in language processing" (p. 1306). Comparing deductive arguments (including categorical and propositional syllogisms) to a baseline condition in which participants had to determine how many of the sentences in an argument had people as subject, the authors did find enhanced activity in Broca's area (BA 45). This was interpreted as evidence for the idea that deductive reasoning may be supported by linguistic mechanisms. However, activity in Broca's area has not systematically been observed in subsequent neuroimaging studies of deductive reasoning. 
On the one hand, while employing relatively similar experimental materials, Goel and colleagues replicated this engagement of Broca's area in deductive reasoning in follow-up studies using PET (Goel, Gold, Kapur, \& Houle, 1998) and functional magnetic resonance imaging (fMRI) (Goel et al., 2000). On the other hand, several other studies have failed to uncover activity in Broca's area during deductive reasoning. For example, comparing deductive reasoning to a language comprehension task involving the exact same arguments, neither Osherson et al. (1998) nor Parsons \& Osherson (2001) reported activity in either left BA 45 or BA 44. Using relational arguments such as "Karen is in front of Larry, Larry is in front of Jane, Is Karen in front of Jane?”, Goel \& Dolan (2001) and Goel, Makale, \& Grafman (2004) found enhanced activity in the parietal cortex but not in Broca's area. Other neuroimaging studies employing relational arguments have also failed to find involvement of Broca's area, instead reporting activity in the posterior parietal cortices (Knauff, Fangmeier, Ruff, \& Johnson-Laird, 2003; Knauff, Mulack, Kassubek, Salih, \& Greenlee, 2002; Prado et al., 2010; Ruff, Knauff, Fangmeier, \& Spreer, 2003). Given the role of the posterior parietal cortex in spatial processing, these results are more consistent with the idea that relational premises are mapped onto spatial mental models than with the idea that it relies on formal rules (which was a possibility acknowledged by Mental Logic theorists, Braine \& O'Brien, 1998). But perhaps more surprising were the results of the first fMRI study that specifically investigated the neural bases of conditional arguments, such as Modus Ponens and Modus Tollens (see Table 1). Noveck et al. (2004) did not report any activity in either left BA 44 or 45 when such conditional arguments (arguably at the heart of the Mental Logic theory, see Table 2) were compared to baseline arguments in which the conclusion was the repetition of a non-overlapping premise (If $\mathrm{P}$ then Q, R, therefore R). Instead, enhanced activity was found in more dorsal fronto-parietal regions (Noveck et al., 2004). 
Overall, early neuroimaging studies provide equivocal evidence for the involvement of Broca's area in deductive reasoning. It is clear that there is some variability between studies, which may come from a number of different sources. First, the type of deductive argument appears to matter. For example, relational arguments are less likely to activate Broca's area that other types of arguments. This was confirmed by a quantitative meta-analysis of the neuroimaging literature on deductive reasoning performed a few years ago (Prado et al., 2011). Compared to studies that specifically investigated the neural bases of categorical or propositional arguments, studies that focused on relational arguments tended to find consistent activation in the posterior parietal cortex rather than Broca's area. In contrast, this meta-analysis found consistent activation of Broca's area across studies that investigated categorical arguments (propositional arguments were found to involve a more dorsal fronto-parietal network).

Second, the studies discussed here all employ control conditions in which sentences are presented to participants. However, as argued elsewhere (Monti \& Osherson, 2012), the amount of linguistic processing required to process these "control" sentences may not always be similar to the amount of linguistic processing that is required when participants have to carefully read premises and conclusions to determine the logical validity of an argument. For instance, early studies in which involvement of Broca's area has been found employed baseline tasks in which participants simply had to determine how many sentences have people as subjects (Goel et al., 1997, 1998). Other studies have used conclusions that were entirely unrelated to the previous premises (Goel et al., 2000). Because sentences in all of those tasks may not be read with the same depth as deductive arguments, any activity observed in Broca's area may be related to differences in terms of reading demands rather than in terms of reasoning per se (Monti \& Osherson, 2012). 
Third, as mentioned earlier, reasoning is a diffuse process that is difficult to isolate temporarily. Studies have relied on different assumptions regarding the exact moment an inference may be best captured. For instance, some studies have used block designs capturing brain activity throughout an entire argument (and even a set of arguments) (Goel et al., 1997, 1998; Osherson et al., 1998; Parsons \& Osherson, 2001), whereas others have modeled brain activity starting from the onset of the conclusion (Goel et al., 2000; Goel \& Dolan, 2001; Noveck et al., 2004) or halfway between the onset of the conclusion and the response (Goel \& Dolan, 2003, 2004). It is even possible that studies have missed the critical moment an inference is made. Specifically, Carlo Reverberi and his colleagues argued that, in theory, an inference can be drawn as soon as the second premise is available and can be integrated with the first premise (Reverberi et al., 2007). For example, the conclusion There is triangle can be inferred as soon as the premises If there is a square then there is triangle and There is square are available to a reasoner. Reverberi and colleagues conducted a series of recent studies based on this assumption.

\section{Evidence for reliance on linguistic processing in neuroimaging studies focusing on the premise processing stage of a deductive argument}

In two studies in which fMRI activity was measured from the onset of this second premise (and compared to activity associated with a premise that could not be integrated), Reverberi and colleagues found enhanced activity in Broca's area (left BAs 44 and 45), both in the case of propositional (Reverberi et al., 2007) and categorical arguments (Reverberi et al., 2010). In another study focusing on inter-individual differences, Reverberi et al. (2012) further found that activity in Broca's area predicted participants' sensitivity to the logical structure of a problem (i.e., how consistent participants were when responding to problems that were superficially different but logically similar). These results led Reverberi and colleagues to 
suggest that Broca's area (together with more dorsal and medial frontal regions) may be "involved in extraction and representation of the formal structure of problems" (p. 1763). Importantly, the authors did not suggest that this region would act in isolation, but rather in cooperation with a more ventral area (left BA 47) that would be involved in selecting and applying logical rules.

Recently, the involvement of Broca's area in the fundamental operations of deduction has further been corroborated by Baggio et al. (2016). In that study, the authors used multivariate pattern analysis to uncover the neural representation of compounds based on the logical connectives and, if, and or. The results show that Broca's area is involved in representing both the surface form and the full logical meaning of these compounds. This led Baggio et al. (2016) to suggest that there is a "shared neural foundation for the cognitive science of language and reasoning" (p. 309).

Results from this set of studies are certainly intriguing and lend some support for the idea that Broca's area may be involved in some aspects of deductive reasoning. However, they suffer from an important caveat. In none of these studies were the brain mechanisms supporting syntactic processing in language formally identified. This is problematic because, even if there is little doubt that Broca's area is involved in syntactic processing (Friederici, 2012; Friederici \& Kotz, 2003; Grodzinsky \& Friederici, 2006), it is also involved in other linguistic functions such as phonological and semantic processing (Vigneau et al., 2006) ${ }^{1}$. In fact, Broca's area may even support functions that appear unrelated to linguistic or syntactic processing, such as visual search (Manjaly et al., 2005), action recognition (Hamzei et al., 2003), movement preparation (Thoenissen, Zilles, \& Toni, 2002), verbal working-memory (Chein, Fissell, Jacobs, \& Fiez, 2002; Rogalsky, Matchin, \& Hickok, 2008), and the processing of ordered information (Van

\footnotetext{
${ }^{1}$ Note, however, that the semantic complexity of a sentence is typically related to its syntactic complexity (Pylkkänen, Brennan, \& Bemis, 2011). Therefore, studies focusing on semantic processing might have syntactic confounds.
} 
Opstal, Fias, Peigneux, \& Verguts, 2009). Therefore, before drawing any conclusion about a link between linguistic processing and deductive reasoning in Broca's area, it is important to formally compare both types of processing within the same participants. I will now turn to studies that precisely investigated this overlap (or lack thereof).

\section{Evidence for reliance on linguistic processing in neuroimaging studies directly comparing brain activity associated with deductive reasoning and linguistic processing}

Monti et al. (2007) were the first to examine brain activity associated with deductive reasoning and brain activity associated with linguistic processing within the same study. To identify the neural correlates of deductive reasoning, the authors compared fMRI activity associated with evaluating propositional arguments in the form of Modus Tollens to activity associated with evaluating propositional arguments in the form of Modus Ponens (see Table 1). Because conclusions in Modus Tollens arguments are typically more difficult to evaluate than conclusions in Modus Ponens arguments, the authors argued that such a contrast provides an index of "reasoning load" that can be used to identify brain regions supporting deductive reasoning. To uncover the neural correlates of linguistic processing, activity associated with reading the first premise of each argument was contrasted to fixation. As expected, this latter contrast was associated with enhanced activity in several frontal, temporal and parietal regions typically associated with reading (including Broca's area). More surprising, however, was the fact that very little overlap was observed between these reading-related brain regions and the brain network identified in the contrast of Modus Tollens versus Modus Ponens arguments. That is, more activity for Modus Tollens than Modus Ponens was found in a fronto-parietal network that included the rostrolateral prefrontal cortex (RLPFC), the medial frontal gyrus, and the posterior parietal cortex. In none of these regions did the authors observed reading-related activity. Overall, these findings (which were replicated across different versions of the task and 
different participants in Monti et al., 2007) appear to provide some evidence for a dissociation between reasoning and linguistic processing. ${ }^{2}$

This dissociation between reasoning and linguistic processing was also partially observed in Prado et al. (2013). In that study, we also aimed to formally identify the brain regions subserving linguistic processing and deductive reasoning within the same participants. Unlike Monti et al. (2007), however, we used an independent word rhyming task as a localizer of the neural mechanisms underlying linguistic processing. For each subject, we identified the specific voxels of Broca's area in which enhanced activity was observed in the rhyming task. Similar to Monti et al. (2007), we used a "reasoning load" approach to test whether enhanced activity could be observed in those voxels during a reasoning task. Specifically, we compared brain activity associated with evaluating a conclusion relying on 3 categorical premises (e.g., All As are Bs, All Bs are Cs, All Cs are Ds, therefore All As are Ds) to brain activity associated with evaluating a conclusion relying on 2 categorical premises (e.g., All As are Bs, All Bs are Cs, All Cs are Ds, therefore All As are Cs). When only considering the voxels that were activated in the rhyming task in Broca's area, we did find more activity for conclusions relying on 3 premises as compared to conclusion relying on 2 premises. In other words, there was some overlap between the rhyming and the reasoning task in Broca's area. However, there was also some important differences between the brain systems supporting reasoning and linguistic processing. First, more activity for conclusions relying on 3 categorical premises as compared to conclusion relying on 2 categorical premises was found in a region of the RLPFC that was not involved in the rhyming task. Second, no overlap between the rhyming and the reasoning task was observed in Broca's area when categorical relations were replaced by linear relations (e.g., A is taller than B, B is taller than C, C is taller than D, therefore A is taller than D). For

\footnotetext{
${ }^{2}$ Activity in a brain network similar to that uncovered in (Monti et al., 2007) was also found in (Rodriguez-Moreno \& Hirsch, 2009). In particular, using categorical syllogisms instead of propositional statements, the authors did not find reasoning-related activity in left BA 44 or 45 . However, there was not task aimed at localizing linguistic processing in that study.
} 
both categorical and relational arguments, however, the number of premises did modulate activity in the RLPFC. Therefore, it is possible that the involvement of Broca's area in deductive reasoning may have more to do with task-specific demands than with the recruitment of content-free rules of inference. For example, it has been argued that categorical relations may rely to a greater extent on verbal working-memory than linear relations because categories are more difficult to map onto a unified representation (Favrel \& Barrouillet, 2000). To some extent, it is possible that a greater reliance on verbal working memory accounts for the enhanced activity in Broca's area in categorical reasoning tasks (see also Mathieu et al., 2015, for a replication of the association between categorical argument and verbal processing in children).

It is important to point out, however, that neither Prado et al. (2013) nor Monti et al. (2007) provide a straightforward test of whether deductive reasoning relies on formal rules of inference similar to those underlying natural language. This is because these studies identified the regions involved in linguistic processing, but not the neural mechanisms specifically supporting syntactic processing in language. A more direct comparison between deductive reasoning and the syntax of language was provided by another study from Monti and colleagues, using a particularly clever design (Monti et al., 2009). In that study, participants were presented with arguments that the authors classified as either 'logical' or 'linguistic'. Both types of arguments involved a premise and a conclusion. They also contained the same 3 elements (X, Y and Z). However, logical and linguistic arguments differed with regards to the kind of inference that was required to assess whether the conclusion was valid or not. Logical arguments were deductive arguments relying on propositional logic. For example, a logical argument was "If both $\mathrm{X}$ and $\mathrm{Z}$ then not $\mathrm{Y}$, therefore If $\mathrm{Y}$ then either not $\mathrm{X}$ or not $\mathrm{Z}$ ". Evaluating the validity of such an argument requires participants to make a logical inference based on an understanding of the meaning of the sentential connectives if ... then, and, or, and not. Linguistic arguments, however, were based on ditransitive verbs such as give, say or take. For 
example, a linguistic argument was "It was $\mathrm{X}$ that $\mathrm{Y}$ saw $\mathrm{Z}$ take, therefore $\mathrm{Z}$ was seen by $\mathrm{Y}$ taking X". Evaluating the validity of such an argument does not rely on a logical inference. Rather, it requires participants to perform a syntactic transformation of the sentences. In sum, comparing brain activity associated with logical and linguistic arguments provides a fairly direct test of whether logical inferences and syntactic processing in language rely on the same set of brain regions. The results indicate that, compared to similar arguments evaluated for grammatical correctness, linguistic and logical arguments elicited enhanced activity in largely separated brain networks. On the one hand, linguistic arguments relied on frontal, temporal and parietal brain regions encompassing Broca's area and Wernicke's area. On the other hand, logical arguments relied on a more restricted sets of brain regions that included the RLPFC and the medial frontal gyrus. Notably, logical arguments were not associated with any specific activity in clusters of the Broca's area that were involved in linguistic arguments. Thus, the authors concluded that "logical inference is not embedded in natural language" (Monti et al., 2009, p. 12554).

\section{The interaction between deductive reasoning and linguistic processing: Putting the pieces} of the puzzle together

It appears relatively clear from the studies above that deductive reasoning does not always rely on the brain regions supporting linguistic (and especially syntactic) processing. At the very least, several studies show that dissociations can be found between the mechanisms underlying some deductive tasks and those supporting language processing. This arguably weakens the claim that deductive reasoning relies on the neural machinery supporting syntactic processing in natural language. Instead, it supports the view that deductive reasoning can operate independently from linguistic mechanisms (Monti \& Osherson, 2012). Nevertheless, several studies reviewed here have found Broca's area to be involved in some deductive 
reasoning tasks (Goel et al., 2000; Goel et al., 1997, 1998; Reverberi et al., 2012; Reverberi et al., 2010; Reverberi et al., 2007). Although some of these results may be driven by baseline issues (e.g., some studies may have employed control conditions that are not entirely matched with experimental conditions in terms of reading demands, see Monti \& Osherson, 2012), not all studies have experimental shortcomings and their findings have to be taken into account. Overall, I would argue that there are two main ways to explain the involvement of Broca's area in these studies.

First, it is possible that any activity in Broca's area during deductive reasoning may reflect some domain-general processes that are not necessarily related to syntactic processing per se. For example, deductive reasoning is likely to rely on verbal working-memory or the processing of ordered information, two cognitive skills that have been associated with Broca's area (Chein et al., 2002; Chein, Ravizza, \& Fiez, 2003; Van Opstal et al., 2009). This may explain the increased activity in Broca's area observed as a function of the number of premises in Prado et al. (2013). The fact that deductive reasoning may tax some domain-general mechanisms that are also be involved in linguistic processing has been acknowledged by Monti and colleagues (Monti et al., 2007). Specifically, these authors have argued that deductive reasoning is supported by a brain network that can be decomposed into core (i.e., domainspecific) and support (i.e., domain-general) areas. Even though Broca's area is not necessarily part of the support network highlighted by Monti et al. (2007), it remains possible that reasoning-related activity in that region reflects such a support role in making deductive inferences.

A second possibility is that the involvement of Broca's area in reasoning studies reflects activity related to syntactic processing that may be task-dependent. In fact, an examination of the type of deductive tasks used in studies that did versus did not find involvement of Broca's area suggests some interesting differences in experimental materials. On the one hand, most of 
the studies that have found involvement of Broca's area tend to have used arguments that are relatively simple and would require the application of one or two basic rules of inference according to the Mental Logic (see Table 2 and red focii in Fig. 2). For instance, Reverberi et al. (2007) presented participants with simple arguments based on the forms Modus Ponens and disjunction elimination. Reverberi et al. (2010) also used simple conditional and categorical arguments that could be solved by the application of basic schemas (Braine \& O'Brien, 1998).

Figure 2 about here

On the other hand, studies that have found reasoning-related activity outside of Broca's area tend to have used tasks that are more complex and would require the application and coordination of several rules of inference (see Table 2 and blue focii in Fig. 2). For instance, Monti et al. (2007) investigated Modus Tollens arguments. As mentioned earlier, Modus Tollens is not an inference that is believed to be part of the basic deductive competence according to the Mental Logic (see Table 2). Understanding such arguments would thus call upon a reasoning strategy involving the coordination of several cognitive steps, known as reduction ad absurdum. Monti et al. (2009) used even more complex arguments embedding disjunctions within Modus Tollens forms. Finally, Prado et al. (2013) found reasoning-related activity outside of Broca's area while using arguments that required the coordination of 3 premises (as compared to 2). In sum, it may be that the complexity of the deductive task is a relevant factor when explaining different patterns of activations in the literature. From a neurocognitive point of view, an increase in the complexity of a deductive argument is associated with an increase in at least 2 components: the number of relations that have to be considered 
simultaneously and the working memory load. For example, Modus Tollens arguments typically require reasoners to maintain and manipulate several relations in working memory. Arguments with 3 premises also arguably require reasoners to consider and maintain in working memory more relations than arguments with 2 premises. $^{3}$

Recently, Coetzee \& Monti (2018) tested whether activity outside of Broca's area (e.g., in the RLPFC) during deductive reasoning could be attributed to an increase in working memory load. That is, the authors set out to compare the brain regions sensitive to an increase in deductive complexity to the brain regions sensitive to an increase in working memory demands. Participants were presented with propositional arguments that were either of the Modus Tollens or Modus Ponens form (see Table 1). In the deductive task, arguments had to be evaluated for logical validity. Similar to Monti et al. (2007), the contrast of Modus Tollens arguments (i.e., complex deductive trials) versus Modus Ponens arguments (i.e., simple deductive trials) provided an index of deductive complexity. In the working memory task, premises and conclusion either had to be maintained in memory (i.e., simple working memory trials) or mentally manipulated (i.e., complex working memory trials) for a subsequent recognition test. The contrast of complex versus simple working memory trials provided an index of working memory demands. The results indicated a crossover interaction between complexity (simple versus complex) and task (deductive versus working memory). That is, whereas deductive complexity modulated activity outside of Broca's area (i.e, in the RLPFC) to a greater extent than working memory complexity, working memory complexity modulated activity in the posterior parietal cortex to a greater extent than deductive complexity. In other

\footnotetext{
${ }^{3}$ This notion of complexity in the domain of reasoning (e.g., an increase in number of logical relations to be considered) differs from the notion of complexity in the linguistic domain. For example, syntactic complexity in the linguistic domain typically refers to factors such as number of embeddings and number of movement operations (Santi \& Grodzinsky, 2010). Importantly, studies have found that increasing the syntactic complexity of sentences is associated with changes of activity within (rather than outside of) Broca's area. Therefore, the notion of complexity itself is unlikely to generalize over language and reasoning.
} 
words, increased activity in the RLPFC as a function of deductive complexity does not appear to be accounted for by an increase in working-memory demands. These findings suggest that activation outside of Broca's area in deductive reasoning studies cannot be merely explained by the complexity of stimuli in terms of working memory.

Coetzee \& Monti (2018)'s results may rule out one important hypothesis concerning the involvement of regions outside of Broca's area (and notably the RLPFC) in some deductive reasoning studies (i.e., the idea that these regions may respond to working memory load). However, the fact remains that an increase in deductive reasoning complexity is typically associated with an increase in the number of logical relations that have to be considered. Interestingly, even though the role of the RLPFC in high-order cognition remains unclear, two major theories posit that this region supports the integration of multiple relations when making a decision (Bunge, Helskog, \& Wendelken, 2009; Krawczyk, Michelle McClelland, \& Donovan, 2010; Wendelken, Nakhabenko, Donohue, Carter, \& Bunge, 2008), as well as the ability to maintain in mind a main goal while working towards secondary goals (Koechlin, Corrado, Pietrini, \& Grafman, 2000; Koechlin, Ody, \& Kouneiher, 2003; Ramnani \& Owen, 2004). Complex deductive arguments often involve dealing with multiple logical relations while working towards finding a valid conclusion. In other words, complex deductive arguments often require greater relational integration and cognitive branching than simple arguments. This may explain the involvement of the RLPFC in those tasks. In contrast, simple deductive arguments (e.g., Modus Ponens) are straightforward and should rely on the instantiation of one single rule according to the Mental Logic (see Table 2). Unlike the kind of arguments that are typically used in studies that focus on deductive complexity (and in which activity in the RLPFC is often found), simple deductive arguments are also routinely used in verbal and written discourse. It is possible that these arguments might have gained - either through ontogeny or phylogeny -- a form of automaticity that makes their underlying syntax 
similar to that of a natural language. In other words, it is possible that simple and complex deductive arguments may rely on qualitatively different mechanisms, with only the former involving the neural substrates of linguistic syntax. This, however, remains to be formally demonstrated.

\section{Conclusion}

The question of whether language and deductive reasoning rely on similar syntactic mechanisms is fascinating because it informs on the broader and fundamental question of whether human thought is embedded in natural language (Monti, 2017). It is also relevant to the reasoning literature because theories have long posited that deductive reasoning might rely on a system of formal rules of inference that can be compared to the linguistic syntax. This probably explains why the study of the relationship between deductive reasoning and language has been at the heart of the neuroimaging literature on reasoning. To date, however, there is no clear evidence that deductive reasoning relies on the neural mechanisms supporting the syntax of language. That is, even though there is support for the idea that some deductive tasks may recruit Broca's area, experimental shortcomings (e.g., baseline conditions that are not matched for reading demands and lack of independent localization of mechanisms supporting the syntax of language) makes it difficult to clearly interpret these findings in terms of overlap between the neural mechanisms for deduction and language. On the contrary, the few studies that have explicitly compared the neural correlates of deductive reasoning to that of language have found largely separated neural networks. It is interesting to note, however, that studies that have found reasoning-related activity outside of Broca's area have largely investigated deductive arguments that are more complex (e.g., involves the integration of more logical relations) than studies that have found reasoning-related activity in Broca's area. Thus, it is possible that the involvement of the neural mechanisms supporting 
linguistic syntax in deductive reasoning may be task-dependent and restricted to simple inferences such as those highlighted in Table 2. A potentially fruitful approach in future studies may then be to investigate the interaction between deductive reasoning and linguistic processing in Broca's area while (i) systematically varying the complexity of the deductive argument and (ii) independently localizing the syntactic mechanisms of language. 


\section{References}

Amunts, K., Schleicher, A., Bürgel, U., Mohlberg, H., Uylings, H., \& Zilles, K. (1999). Broca's region revisited: cytoarchitecture and intersubject variability. Journal of Comparative Neurology, 412(2), 319-341.

Baggio, G., Cherubini, P., Pischedda, D., Blumenthal, A., Haynes, J. D., \& Reverberi, C. (2016). Multiple neural representations of elementary logical connectives. Neuroimage, 135, 300-310. doi:10.1016/j.neuroimage.2016.04.061

Ben-Shachar, M., Hendler, T., Kahn, I., Ben-Bashat, D., \& Grodzinsky, Y. (2003). The neural reality of syntactic transformations: evidence from functional magnetic resonance imaging. Psychol Sci, 14(5), 433-440. doi:psci_1459 [pii]

Ben-Shachar, M., Palti, D., \& Grodzinsky, Y. (2004). Neural correlates of syntactic movement: converging evidence from two fMRI experiments. Neuroimage, 21(4), 1320-1336. doi:10.1016/j.neuroimage.2003.11.027

S1053811903007699 [pii]

Braine, M. D. (1990). The"natural logic" approach to reasoning. In W. F. Overton (Ed.), Reasoning, necessity and logic: Developmental perspectives (pp. 133-157). Hillsdale, N.J.: Erlbaum.

Braine, M. D., \& O'Brien, D. (1998). Mental Logic. Mahwah, NJ: Erlbaum.

Braine, M. D. S. (1998). Steps towards a mental-predicate logic. In M. D. S. Braine \& B. J. O'Brien (Eds.), Mental logic (pp. 273-331). Mahwah, NJ:: Lawrence Erlbaum Associates.

Bunge, S., Helskog, E., \& Wendelken, C. (2009). Left, but not right, rostrolateral prefrontal cortex meets a stringent test of the relational integration hypothesis. Neuroimage, 46(1), 338-342. doi:S1053-8119(09)00112-8 [pii]

10.1016/j.neuroimage.2009.01.064

Chein, J. M., Fissell, K., Jacobs, S., \& Fiez, J. A. (2002). Functional heterogeneity within Broca's area during verbal working memory. Physiol Behav, 77(4-5), 635-639.

Chein, J. M., Ravizza, S. M., \& Fiez, J. A. (2003). Using neuroimaging to evaluate models of working memory and their implications for language processing. J Neurolinguist, 16, 315-339.

Coetzee, J. P., \& Monti, M. M. (2018). At the core of reasoning: Dissociating deductive and non-deductive load. Hum Brain Mapp, 39(4), 1850-1861. doi:10.1002/hbm.23979

Ellsworth, P., Holyoak, K., \& Morrison Jr, R. (2005). Legal Reasoning. In The Cambridge Handbook of Thinking and Reasoning (pp. 685-704). 
Fadiga, L., Craighero, L., \& D'Ausilio, A. (2009). Broca's area in language, action, and music. Ann N Y Acad Sci, 1169, 448-458.

Favrel, J., \& Barrouillet, P. (2000). On the Relation Between Representations Constructed From Text Comprehension and Transitive Inference Production* 1. Journal of Experimental Psychology: Learning.

Friederici, A. D. (2012). The cortical language circuit: from auditory perception to sentence comprehension. Trends Cogn Sci, 16(5), 262-268. doi:10.1016/j.tics.2012.04.001

Friederici, A. D., Fiebach, C. J., Schlesewsky, M., Bornkessel, I. D., \& von Cramon, D. Y. (2006). Processing linguistic complexity and grammaticality in the left frontal cortex. Cereb Cortex, 16(12), 1709-1717. doi:bhj106 [pii]

10.1093/cercor/bhj106

Friederici, A. D., \& Kotz, S. A. (2003). The brain basis of syntactic processes: functional imaging and lesion studies. Neuroimage, 20 Suppl 1, S8-17. doi:S1053811903005226 [pii]

Friederici, A. D., Ruschemeyer, S. A., Hahne, A., \& Fiebach, C. J. (2003). The role of left inferior frontal and superior temporal cortex in sentence comprehension: localizing syntactic and semantic processes. Cereb Cortex, 13(2), 170-177.

Goel, V. (2007). Anatomy of deductive reasoning. Trends Cogn. Sci. (Regul. Ed.), 11(10), 435-441. doi:10.1016/j.tics.2007.09.003

Goel, V., Buchel, C., Frith, C., \& Dolan, R. J. (2000). Dissociation of mechanisms underlying syllogistic reasoning. Neuroimage, 12(5), 504-514. doi:10.1006/nimg.2000.0636

S1053-8119(00)90636-0 [pii]

Goel, V., \& Dolan, R. J. (2001). Functional neuroanatomy of three-term relational reasoning. Neuropsychologia, 39(9), 901-909.

Goel, V., \& Dolan, R. J. (2003). Explaining modulation of reasoning by belief. Cognition, $87(1), \mathrm{B} 11-22$.

Goel, V., \& Dolan, R. J. (2004). Differential involvement of left prefrontal cortex in inductive and deductive reasoning. Cognition, 93(3), B109-121.

doi:10.1016/j.cognition.2004.03.001

Goel, V., Gold, B., Kapur, S., \& Houle, S. (1997). The seats of reason? An imaging study of deductive and inductive reasoning. Neuroreport, 8(5), 1305-1310.

Goel, V., Gold, B., Kapur, S., \& Houle, S. (1998). Neuroanatomical correlates of human reasoning. J Cogn Neurosci, 10(3), 293-302.

Goel, V., Makale, M., \& Grafman, J. (2004). The hippocampal system mediates logical reasoning about familiar spatial environments. J Cogn Neurosci, 16(4), 654-664. doi:10.1162/089892904323057362 
Goodwin, G. P., \& Johnson-Laird, P. N. (2005). Reasoning about relations. Psychol Rev, 112(2), 468-493. doi:2005-02750-007 [pii]

10.1037/0033-295X.112.2.468

Grodzinsky, Y., \& Friederici, A. D. (2006). Neuroimaging of syntax and syntactic processing. Curr Opin Neurobiol, 16 240-246.

Grodzinsky, Y., \& Santi, A. (2008). The battle for Broca's region. Trends Cogn Sci, 12(12), 474-480. doi:S1364-6613(08)00222-2 [pii]

10.1016/j.tics.2008.09.001

Hagert, G. (1984). Modeling mental models: experiments in cognitive modeling spatial reasoning. In T. O'Shea (Ed.), Advances in Artificial Intelligence (pp. 389-398). Amsterdam: North-Holland.

Hamzei, F., Rijntjes, M., Dettmers, C., Glauche, V., Weiller, C., \& Buchel, C. (2003). The human action recognition system and its relationship to Broca's area: an fMRI study. Neuroimage, 19(3), 637-644.

Johnson-Laird, P. N. (1999). Formal rules verses mental models in reasoning. In R. J. Sternberg (Ed.), The nature of cognition. Cambridge, MA: MIT Press.

Johnson-Laird, P. N. (2010). Against logical form. Psychologica Belgica, 50(3\&4), 193-221.

Knauff, M., Fangmeier, T., Ruff, C. C., \& Johnson-Laird, P. N. (2003). Reasoning, models, and images: behavioral measures and cortical activity. J Cogn Neurosci, 15(4), 559573. doi:10.1162/089892903321662949

Knauff, M., Mulack, T., Kassubek, J., Salih, H. R., \& Greenlee, M. W. (2002). Spatial imagery in deductive reasoning: a functional MRI study. Brain Res Cogn Brain Res, 13(2), 203-212.

Koechlin, E., Corrado, G., Pietrini, P., \& Grafman, J. (2000). Dissociating the role of the medial and lateral anterior prefrontal cortex in human planning. Proc Natl Acad Sci U $S$ A, 97(13), 7651-7656. doi:10.1073/pnas. 130177397

130177397 [pii]

Koechlin, E., Ody, C., \& Kouneiher, F. (2003). The architecture of cognitive control in the human prefrontal cortex. Science, 302(5648), 1181-1185.

doi:10.1126/science. 1088545

302/5648/1181 [pii]

Krawczyk, D. C., Michelle McClelland, M., \& Donovan, C. M. (2010). A hierarchy for relational reasoning in the prefrontal cortex. Cortex. doi:10.1016/j.cortex.2010.04.008

Lea, B. (1995). On-line evidence for elaborative logical inference in text. Journal of Experimental Psychology: Leaning, Memory and Cognition, 6, 14691482.

Lea, R. B., O'Brien, D. P., Fisch, S. M., Noveck, I. A., \& Braine, M. D. S. (1990). Predicting propositional-like inferences in text-comprehension. . J. Mem. Lang. , 29(361-387). 
Manjaly, Z. M., Marshall, J. C., Stephan, K. E., Gurd, J. M., Zilles, K., \& Fink, G. R. (2005). Context-dependent interactions of left posterior inferior frontal gyrus in a local visual search task unrelated to language. Cogn Neuropsychol, 22(3), 292-305.

doi: $10.1080 / 02643290442000149$

Mathieu, R., Booth, J. R., \& Prado, J. (2015). Distributed neural representations of logical arguments in school-age children. Hum Brain Mapp, 36(3), 996-1009. doi:10.1002/hbm.22681

Mercier, H., \& Sperber, D. (2011). Why do humans reason? Arguments for an argumentative theory. Behav Brain Sci, 34(2), 57-74; discussion 74-111.

doi:10.1017/S0140525X10000968

Meyer, M., Friederici, A. D., \& von Cramon, D. Y. (2000). Neurocognition of auditory sentence comprehension: event-related fMRI reveals sensitivity to syntactic violations and task demands. Cogn Brain Res, 9(19-33).

Michal, A., \& Ruhama, E. (2008). Deductive reasoning: in the eye of the beholder. Educational Studies in Mathematics, 69. doi:10.1007/s10649-008-9136-2

Monti, M., \& Osherson, D. (2012). Logic, language and the brain. Brain Research, 1428, 3342. doi:10.1016/j.brainres.2011.05.061

Monti, M. M. (2017). The role of language in structure-dependent cognition. In M. Moddy (Ed.), Neural mechanisms of language. New York, NY: Springer.

Monti, M. M., Osherson, D. N., Martinez, M. J., \& Parsons, L. M. (2007). Functional neuroanatomy of deductive inference: a language-independent distributed network. Neuroimage, 37(3), 1005-1016. doi:10.1016/j.neuroimage.2007.04.069

Monti, M. M., Parsons, L. M., \& Osherson, D. N. (2009). The boundaries of language and thought in deductive inference. Proc. Natl. Acad. Sci. U.S.A., 106(30), 12554-12559. doi:10.1073/pnas.0902422106

Noveck, I. A., Goel, V., \& Smith, K. W. (2004). The neural basis of conditional reasoning with arbitrary content. Cortex, 40(4-5), 613-622.

Nunes, T., Bryant, P., Evans, D., Bell, D., Gardner, S., Gardner, A., \& Carraher, J. (2007). The contribution of logical reasoning to the learning of mathematics in primary school. British Journal of Developmental Psychology, 25, 147-166.

Oaksford, M. (2015). Imaging deductive reasoning and the new paradigm. Front Hum Neurosci, 9, 101. doi:10.3389/fnhum.2015.00101

Oaksford, M., \& Chater, N. (2001). The probabilistic approach to human reasoning. Trends Cogn Sci, 5(8), 349-357.

Oaksford, M., \& Chater, N. (2007). Bayesian rationality. The probabilistic approach to human reasoning. Oxford, England: Oxford University Press. 
Osherson, D., Perani, D., Cappa, S., Schnur, T., Grassi, F., \& Fazio, F. (1998). Distinct brain loci in deductive versus probabilistic reasoning. Neuropsychologia, 36(4), 369-376. doi:S0028-3932(97)00099-7 [pii]

Parsons, L., \& Osherson, D. (2001). New Evidence for Distinct Right and Left Brain Systems for Deductive versus Probabilistic Reasoning. Cerebral cortex (New York, N.Y. : 1991), 11(10), 954-965. doi:10.1093/cercor/11.10.954

Polk, T. A., \& Newell, A. (1995). Deduction as verbal reasoning. Psychol. Rev., 102(533566).

Prado, J., Chadha, A., \& Booth, J. (2011). The brain network for deductive reasoning: a quantitative meta-analysis of 28 neuroimaging studies. Journal of cognitive neuroscience, 23(11), 3483-3497. doi:10.1162/jocn_a_00063

Prado, J., Mutreja, R., \& Booth, J. R. (2013). Fractionating the Neural Substrates of Transitive Reasoning: Task-Dependent Contributions of Spatial and Verbal Representations. Cereb Cortex, 23(3), 499-507.

Prado, J., Spotorno, N., Koun, E., Hewitt, E., Van Der Henst, J. B., Sperber, D., \& Noveck, I. A. (2015). Neural interaction between logical reasoning and pragmatic processing in narrative discourse. Journal of cognitive neuroscience, 27, 692-704.

Prado, J., Van Der Henst, J.-B., \& Noveck, I. A. (2010). Recomposing a fragmented literature: how conditional and relational arguments engage different neural systems for deductive reasoning. Neuroimage, 51(3), 1213-1221. doi:10.1016/j.neuroimage.2010.03.026

Pylkkänen, L., Brennan, J., \& Bemis, D. K. (2011). Grounding the cognitive neuroscience of semantics in linguistic theory. Language and Cognitive Processes, 26(9), 1317-1337.

Ramnani, N., \& Owen, A. (2004). Anterior prefrontal cortex: insights into function from anatomy and neuroimaging. Nat Rev Neurosci, 5(3), 184-194. doi:10.1038/nrn1343

Reverberi, C., Bonatti, L. L., J., F. R. S., Paulesu, E., Cherubini, P., \& Macaluso, E. (2012). Large scale brain activations predict reasoning profiles. Neuroimage, 59, 1752-1764.

Reverberi, C., Cherubini, P., Frackowiak, R. S. J., Caltagirone, C., Paulesu, E., \& Macaluso, E. (2010). Conditional and syllogistic deductive tasks dissociate functionally during premise integration. Hum Brain Mapp. doi:10.1002/hbm.20947

Reverberi, C., Cherubini, P., Rapisarda, A., Rigamonti, E., Caltagirone, C., Frackowiak, R. S. J., . . Paulesu, E. (2007). Neural basis of generation of conclusions in elementary deduction. Neuroimage, 38(4), 752-762. doi:10.1016/j.neuroimage.2007.07.060

Reverberi, C., Rusconi, P., Paulesu, E., \& Cherubini, P. (2009). Response demands and the recruitment of heuristic strategies in syllogistic reasoning. $Q J$ Exp Psychol (Colchester), 62(3), 513-530. doi:10.1080/17470210801995010 
Reverberi, C., Shallice, T., D'Agostini, S., Skrap, M., \& Bonatti, L. L. (2009). Cortical bases of elementary deductive reasoning: inference, memory, and metadeduction. Neuropsychologia, 47(4), 1107-1116. doi:10.1016/j.neuropsychologia.2009.01.004

Rips, L. (1994). The Psychology of Proof. Cambridge, MA: MIT Press.

Roder, B., Stock, O., Neville, H., Bien, S., \& Rosler, F. (2002). Brain activation modulated by the comprehension of normal and pseudo-word sentences of different processing demands: a functional magnetic resonance imaging study. Neuroimage, 15(4), 10031014. doi:10.1006/nimg.2001.1026

S1053811901910262 [pii]

Rodriguez-Moreno, D., \& Hirsch, J. (2009). The dynamics of deductive reasoning: an fMRI investigation. Neuropsychologia, 47(4), 949-961. doi:S0028-3932(08)00363-1 [pii]

10.1016/j.neuropsychologia.2008.08.030

Rogalsky, C., Matchin, W., \& Hickok, G. (2008). Broca's area, sentence comprehension, and working memory: an fMRI Study. Front Hum Neurosci, 2, 14.

doi:10.3389/neuro.09.014.2008

Ruff, C. C., Knauff, M., Fangmeier, T., \& Spreer, J. (2003). Reasoning and working memory: common and distinct neuronal processes. Neuropsychologia, 41(9), 1241-1253.

Santi, A., \& Grodzinsky, Y. (2010). fMRI adaptation dissociates syntactic complexity dimensions. Neuroimage, 51(4), 1285-1293.

Schwartz, F., Epinat-Duclos, J., Léone, J., \& Prado, J. (2017). The neural development of conditional reasoning in children: Different mechanisms for assessing the logical validity and likelihood of conclusions. Neuroimage, 163, 264-275.

Stollstorff, M., Vartanian, O., \& Goel, G. (2012). Levels of conflict in reasoning modulate right lateral prefrontal cortex. Brain Research, 1428, 24-32.

Stromswold, K., Caplan, D., Alpert, N., \& Rauch, S. (1996). Localization of syntactic comprehension by positron emission tomography. Brain Lang, 52(3), 452-473. doi:S0093-934X(96)90024-3 [pii]

$10.1006 /$ brln.1996.0024

Tettamanti, M., \& Weniger, D. (2006). Broca's area: a supramodal hierarchical processor? Cortex, 42(4), 491-494.

Thoenissen, D., Zilles, K., \& Toni, I. (2002). Differential involvement of parietal and precentral regions in movement preparation and motor intention. J Neurosci, 22(20), 9024-9034.

Ullman, M. T. (2001). A neurocognitive perspective on language: the declarative/procedural model. Nat Rev Neurosci, 2(10), 717-726. doi:10.1038/35094573

35094573 [pii] 
Van Opstal, F., Fias, W., Peigneux, P., \& Verguts, T. (2009). The neural representation of extensively trained ordered sequences. Neuroimage, 47(1), 367-375.

doi:10.1016/j.neuroimage.2009.04.035

Vigneau, M., Beaucousin, V., Herve, P. Y., Duffau, H., Crivello, F., Houde, O., . . TzourioMazoyer, N. (2006). Meta-analyzing left hemisphere language areas: phonology, semantics, and sentence processing. Neuroimage, 30(4), 1414-1432. doi:10.1016/j.neuroimage.2005.11.002

Wendelken, C., Nakhabenko, D., Donohue, S., Carter, C., \& Bunge, S. (2008). "Brain is to thought as stomach is to ??": investigating the role of rostrolateral prefrontal cortex in relational reasoning. J Cogn Neurosci, 20(4), 682-693. doi:10.1162/jocn.2008.20055

Wulff, H. (1986). Rational Diagnosis and Treatment. J Med Philos, 11(2), 123-134. 


\section{Figures}

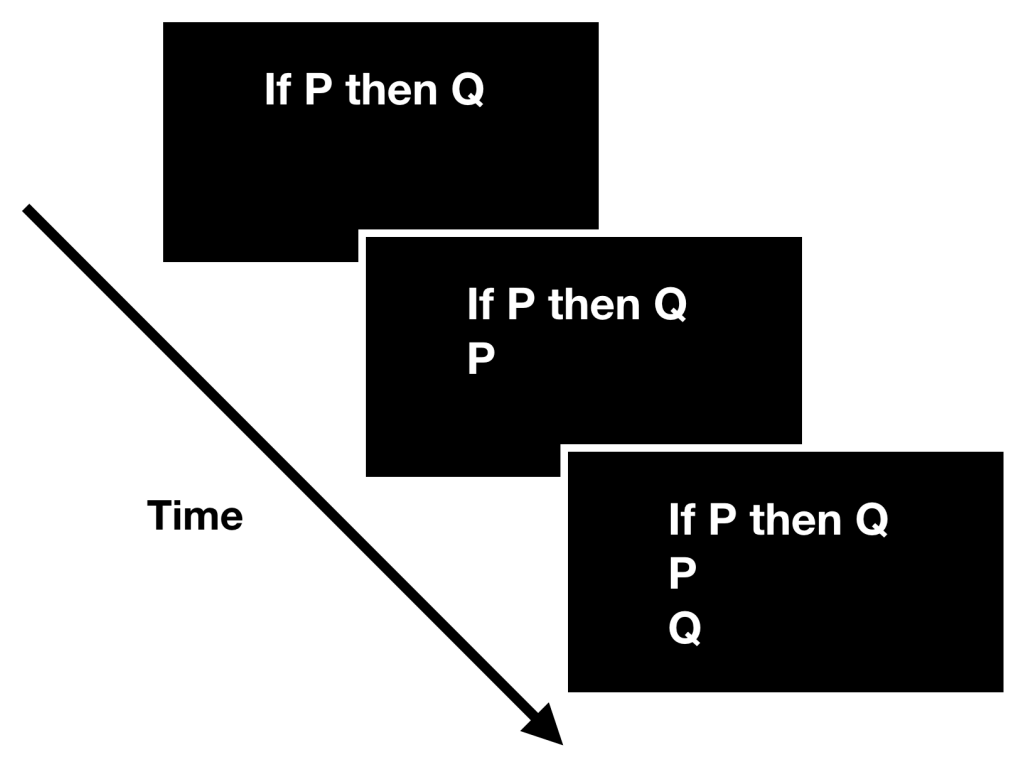

Figure 1. Typical paradigm used to investigate the neural bases of deductive reasoning.

Premises and conclusion are presented sequentially. Brain activity is measured either upon the presentation of the second premise $(\mathrm{P})$ or conclusion $(\mathrm{Q})$. 


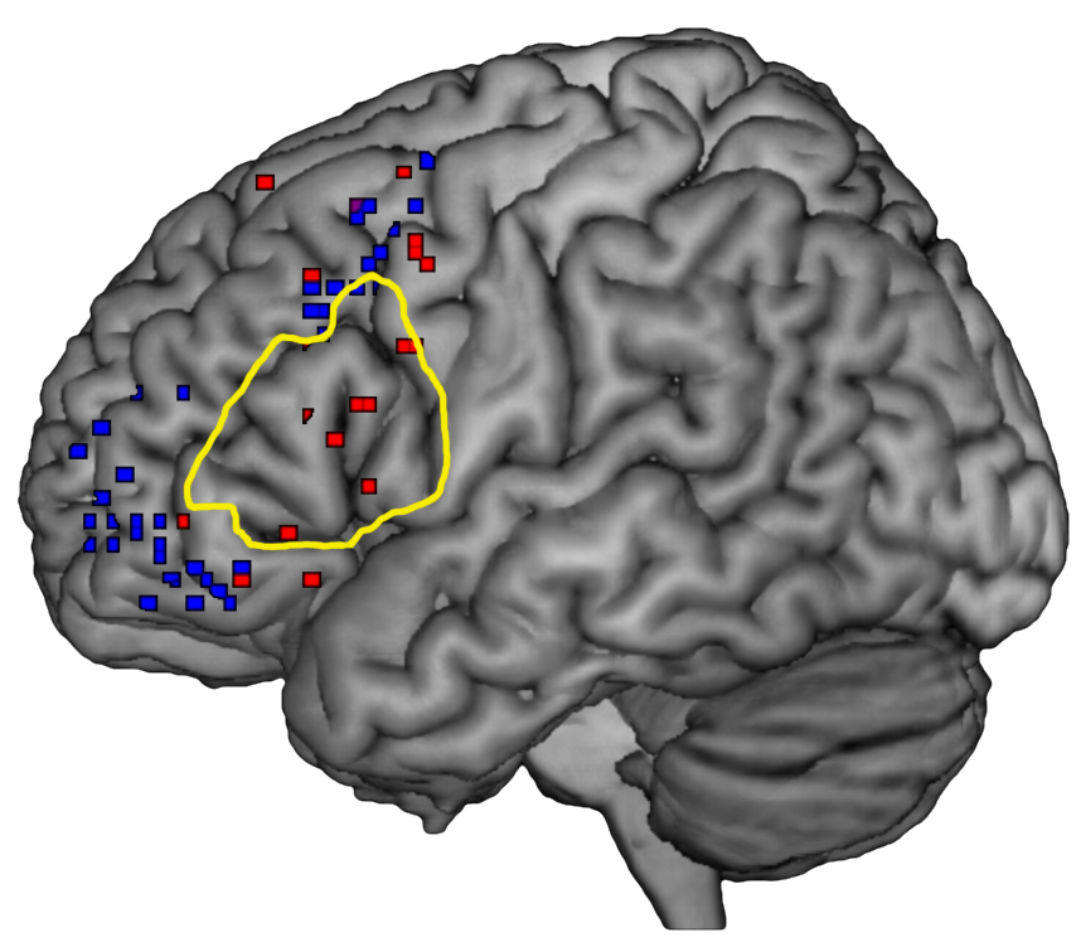

Figure 2. Distribution of activation peaks in studies employing relatively simple propositional (or categorial) arguments (red) and studies employing relatively complex propositional arguments (blue) in the left frontal cortex. Coordinates of studies employing relatively simple arguments are taken from Reverberi and colleagues (Baggio et al., 2016; Reverberi et al., 2012; Reverberi et al., 2010; Reverberi et al., 2007) while coordinates of studies employing relatively complex arguments are taken from Monti and colleagues (Coetzee \& Monti, 2018; Monti et al., 2007; Monti et al., 2009). A yellow outline delineates Broca's area, defined as Brodmann areas 44 and 45 according to the cytoarchitectonic map of Amunts et al. (1999). 


\section{Tables}

Table 1. Examples of deductive arguments as a function of their logical form

\begin{tabular}{|c|c|}
\hline Logical form & Example \\
\hline \multirow[t]{3}{*}{ Modus Ponens } & Premise 1: If there is a circle then there is a triangle \\
\hline & Premise 2: There is a circle \\
\hline & Conclusion: Therefore, there is a triangle \\
\hline \multirow[t]{3}{*}{ Modus Tollens } & Premise 1: If there is a circle then there is a triangle \\
\hline & Premise 2: There is not a triangle \\
\hline & Conclusion: Therefore, there is not a circle \\
\hline \multirow[t]{3}{*}{ Disjunction elimination } & Premise 1: There is a circle or there is a triangle \\
\hline & Premise 2: There is not a circle \\
\hline & Conclusion: Therefore, there is a triangle \\
\hline \multirow[t]{3}{*}{ Relational argument } & Premise 1: The circle is larger the triangle \\
\hline & Premise 2: The triangle is larger the square \\
\hline & Conclusion: Therefore, the circle is larger than the square \\
\hline \multirow[t]{3}{*}{ Categorical Argument } & Premise 1: All tables are triangles \\
\hline & Premise 2: All triangles are blue \\
\hline & Conclusion: Therefore, all tables are blue \\
\hline
\end{tabular}


Table 2. The 12 elementary rules (i.e., schemas) from the Mental Logic

\begin{tabular}{ccc} 
Schema & Premises & Conclusion \\
\hline 1 & Not not-P & $\mathrm{P}$ \\
2 & If P or Q then R; P & $\mathrm{Q}$ \\
3 & P or Q; not P & Not-Q \\
4 & Not both P and Q; P & R \\
5 & P or Q; If P then R; If Q then R & R or S \\
6 & P or Q; If P then R; If Q then S & Q \\
7 & If P then Q; P & P and Q \\
8 & P; Q & P \\
9 & P and Q & (P and Q) or (P and R) \\
10 & P and (Q or R) & Incompatibility \\
11 & P or Q; Not-P; Not-Q & Incompatibility \\
12 & & \\
\hline
\end{tabular}

